\title{
Supportive Regulations and Standards to Encourage a Level Playing Field for the Bio-based Economy
}

\author{
Luana Ladu, TU Berlin, Berlin, Germany
}

Minique Vrins, NEN, Delft, Netherlands

\begin{abstract}
A favourable regulatory and standardization framework is a prerequisite for establishing a cuttingedge bio-based economy in Europe. This article presents an overview of existing regulatory and standardization barriers that are hampering the market uptake of bio-based products. Among others, they include: i) the lack of a level playing field vis-à-vis biofuels and fossil-based products; ii) the lack of generally accepted end-of-life routes for bio-based products; and iii) the existence of standards designed for fossil-based materials that do not match market practises. Based on the results of a 2-round Delphi survey, proposals are formed to overcome the identified barriers. These solutions are thereafter verified by stakeholders through additional interviews and a workshop. Finally, recommendations were drafted to update the current regulatory and standardization framework. More specifically, the adoption of relevant principles for the cascading use of biomassthe use of alternative innovative feedstock (e.g. waste) and the update of existing standards (e.g. compostability) are proposed.
\end{abstract}

\section{KEYWORDS}

Bio-Based Economy, Cascading Principles, Comspostability, Delphi Survey, Level Playing Field, Regulatory Framework, Standards, Waste as Feedstock

\section{INTRODUCTION}

Improved and innovative ways of producing and consuming food, products and materials are needed for decoupling economic growth from resource depletion and environmental impact (European Commission, 2018). As stated in the Strategic Innovation and Research Agenda (BBI JU, 2017), a sustainable bio-based economy in Europe could provide environmental, social and economic benefits, and therefore contribute towards achieving a carbon-neutral future consistent with the Paris Agreement.

A supportive regulatory and standardization framework is a prerequisite for establishing such a sustainable and efficient bio-based economy in Europe. Regulation should enable rather than impede innovation for unlocking the potential of the bio-based economy, and should ensure a level playing field for competition between bio-based and fossil-based industries.

This paper identifies existing regulatory and standardization gaps and bottlenecks affecting bio-based industries; it is based on in-depth interviews with selected value chain representatives, followed by a 2-round Delphi survey. This survey focused on the identification of barriers hampering the market uptake of bio-based products, as well as potential innovations (drivers of change) that are expected to play an important role in scaling up the industry. The results of the 2-round Delphi survey provided the basis for the formulation of specific recommendations for updating existing standards 
and regulations, and for the development of new regulations to fill important gaps, in particular in the identified fields of innovation.

The paper studies the importance of different elements of a supportive regulatory framework for the bio-based economy that are needed for establishing a level playing field for bio-based products. Regulatory and standardization related suggestions for enhancing principles of cascading use of biomass, and for enhancing the use of waste as a feedstock, are elaborated. In addition, solutions for existing gaps in standards are identified and proposed.

The paper is organized as follows: first, the proposed methodology is explained, followed by a description of identified existing barriers. Thereafter, the results on the required elements for a supportive regulatory framework are illustrated, and finally, the conclusions and recommendations of this study are presented.

\section{LITERATURE REVIEW, RESEARCH OBJECTIVES AND METHODOLOGY}

Systematic foresight investigations with a focus on technologies, regulations and standards allow better decision-making towards the enabling of a bio-based economy (Ladu and Quitzow, 2017). It is indeed a challenge to establish a flexible regulatory framework that can adapt to the pace of change of innovations and new technologies. Foresight investigations can be defined as a structured dialogue among stakeholders on possible future developments (Giaoutzi and Sapio, 2013). It represents a relevant policy instrument and decision-making tool based on the following features: anticipation, participation, networking, vision and action (Vecchiato and Roveda, 2014). Blind (2008) proposed three methodologies for conducting regulatory foresight:

i) A first approach that uses science and technology indicators for identifying possible fields that may cause challenges for the regulatory framework.

ii) A second approach based on surveys that enable regulatory bodies to identify future needs for regulations.

iii) A Delphi methodology involving multiple survey rounds.

For this paper, we adopted a combined methodology for conducting regulatory foresight, including preliminary expert interviews (see Ladu and Clavell, 2018) and a 2-round Delphi exercise (see Ladu and Clavell, 2019). The Delphi method is based on structured surveys and makes use of information obtained from the experience and knowledge of the participants (JRC, 2015). It aims to synthesize the collective expertise of the respondents (Linstone and Turoff, 2002), and includes two or more rounds to validate and refine the results of initial communications with the participants. The formalization of the methodology, the amount of data, the number of experts involved, and the fact that diverging opinions are partially hidden behind the main converging one, make it a popular and credible approach for policy makers (JRC, 2015).

By means of preliminary interviews, experts' opinions were collected with the objective of identifying existing market barriers that are currently hampering the market uptake of bio-based products, and anticipating upcoming innovations that would have a positive impact in the further development of the sector. Special attention was paid to existing regulatory, standardization and investment barriers, which could delay these new developments, and which should be addressed and possibly removed in order to support further deployment of the bio-based economy. Overall, 20 key sector experts were interviewed, including 10 experts from industry and 10 experts from academia.

Based on these results, a 2-round Delphi study was designed and conducted to identify required updates of the regulatory and standardization framework for supporting a full deployment of innovation potentials and for unlocking investments in the bio-based economy. 
The aim of the first round was to identify experts' opinions on which elements should be included in a supportive standardization and policy framework for bio-based products. In total, 887 experts from academia, industry, NGOs, and experts working on bio-based economy related topics, were invited to participate in the survey.

Considering that the literature fails to debate the practicalities of defining "experts" for Delphi exercises (Baker et al., 2006), for the purpose of this study, we adopted different actions to ensure rigor in the selection of the experts. The first identification of experts was done directly by the author among their institutions' internal databases. In addition, coordinators and partners' institutions of relevant European related projects (e.g., BBI JU projects) and participants in important related conferences in Europe (e.g., the $12^{\text {th }}$ European Bioplastic Conference and the Global Bioeconomy Summit) were invited to participate. In order to reach more experts, a link to the survey was also published in several newsletters. See Figure 1 for the overview of participating experts in the first round:

In total, 100 experts completed the first round, which included only open questions. The majority of the respondents (45\%) came from Germany, from both academia (36\%) and industry (34\%). In terms of expertise, most of them declared to be bioeconomy experts $(70 \%)$.

The second round aimed to recollect expert's opinion on the relevance of the important features that a supportive regulatory framework should include, as well as the relevance of other identified actions needed for establishing a level playing field for bio-based products. It was distributed only among the experts that wished to participate in a second round. See Figure 2 for the overview of participating experts in the second round.

In total, 35 experts completed the second round of the survey, more than 50\% coming from Germany (54.3\%). Most of the experts worked in academia (45\%) and industry (20\%).

\section{EXISTING MARKET BARRIERS}

\section{Regulatory and Market Barriers}

Consistent long-term policy goals and supportive policy instruments needed for the transition to a circular bio-based economy are currently missing. For example, there are no legislative mechanisms to support and regulate the use of biomass for producing chemicals and products (e.g., effective demand support policies in favour of bio-based products). The lack of these mechanisms hampers the development of markets dedicated to bio-based products. Moreover, the EC's Renewable Energy Directive (RED) of 2009 and their new proposal for RED II (2021-2030), includes provisions that favour the production of biofuels over bio-based products within Europe. Incentives for biofuel production favour feedstock production for the biofuel industry and limit the availability of biomass

Figure 1. Generalities of the participants of the first Delphi round
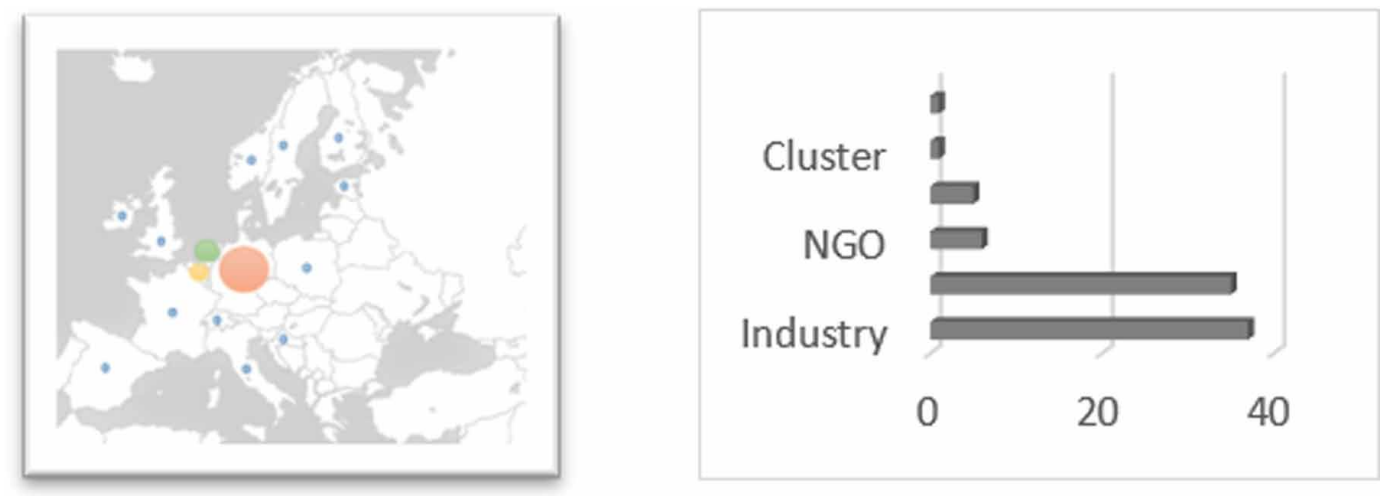

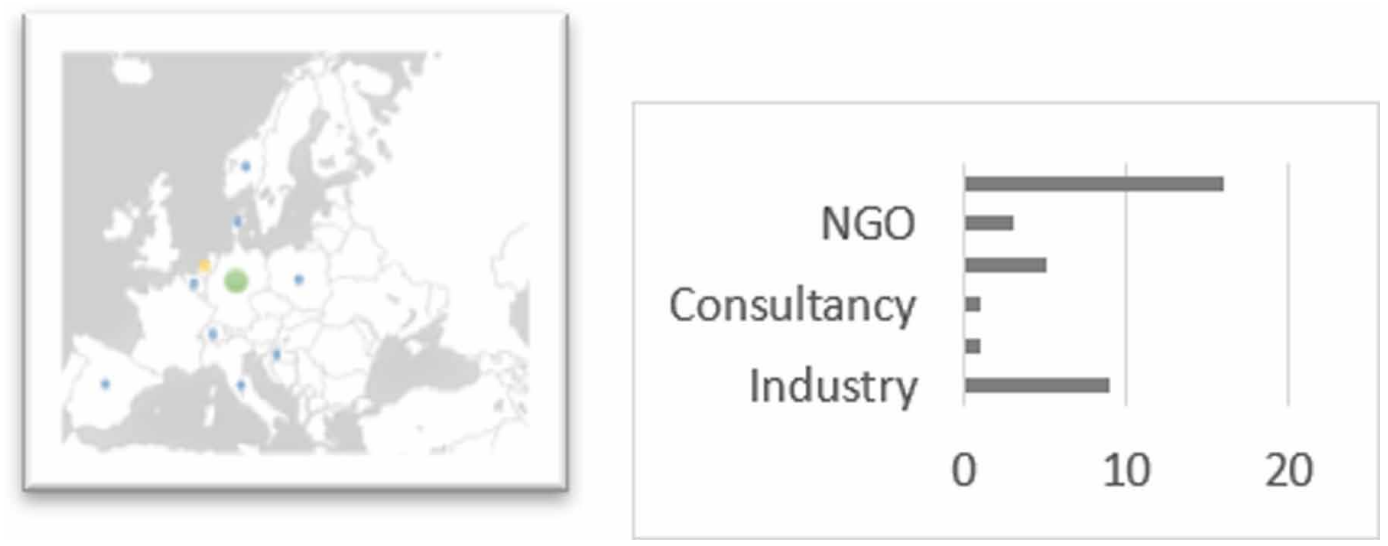

for the bio-based product industry. Moreover, the bio-based product industry is negatively affected by the controversy around the use of food crops for any other uses than food and feed has been raised by NGOs, consumers and policy makers. This is also a result of strong incentives for biofuel production.

There is also a lack of a level playing field between bio-based products and fossil-based products. Bio-based products are expected to provide conformity to high standards concerning sustainability, while fossil-based counterparts are not required to conform to any standards. The costs of externalities linked to the production and consumption of fossil products (e.g., the damage to the environment) are currently not carried by the producers of these products, rather by the entire society. The lack of pricing of these externalities creates a price advantage for fossil products over bio-based products. In this regard, bio-based products are prevented from taking advantage of the existing related environmental benefits.

Numerous hurdles mentioned by the experts are linked to the end-of-life of bio-based products (Bos et al., 2018). Frequently, there is no general agreement as to which end-of-life option (e.g., recycling, digestion, composting) for a given bio-based product is the most preferable route. This lack of clarity creates confusion throughout the value chain, and especially for consumers. There are currently no harmonized rules at European or even at national/regional level on how to dispose of bio-based products, and conflicting interests among different players within the end-of-life value chain (e.g., recyclers, composters) exist.

\section{Barriers Around Certification and Standards}

The International Standardization Organization (ISO) defines standards as:

documented agreements containing technical specifications or other precise criteria to be used consistently as rules, guidelines or definitions, to ensure that materials, products, processes and services are fit for their purpose (Definition of $I S O^{1}$ ).

These agreements provide people and organizations with a basis for mutual understanding, and are used as tools to facilitate communication, measurement, commerce and manufacturing. In an ideal situation, standards are developed in a collaborative process that includes manufacturers, users, consultants, governments and other interested parties. Therefore, standardization bodies seek to have all parties concerned at the table during the development of standards. When stakeholders are not represented during the development of the standards, outcomes may be less than optimal for stakeholders that are expected to use the standards in the market. As the development of a standard 
can take several years, it is also possible that, during this time, processes have evolved that make the standard already outdated once it is published. In both situations, the standard does not represent the actual situation in practice. An example of such a mismatch is the EN 13432 for packaging. This standard prescribes that biodegradable products should compost within 12 weeks in a secured composting cycle. When biodegradable products comply with the standard they can receive (one of the many) certificates that claim that the product will degrade within 12 weeks in a secured composting cycle. However, the composting cycles run by composters are currently much shorter than 12 weeks; around 2 to 3 weeks at most. In practice, this means that composters sieve out all (biodegradable) products beforehand. In other words, even though the products are certified according to the standard, these products will be incinerated.

Another identified barrier is that for many years, product standards (that specify requirements to be fulfilled by a product or a group of products) have been developed to determine its fitness for purpose. Most of these standards were developed when fossil-based products were "mainstream" products. Requirements in the standard with which the product needs to comply are, for example, based on the characteristics of plastic. To demonstrate fitness for purpose, new materials are tested against the characteristics of plastic, as developed for pre-existing fossil-based plastic materials (e.g., plastic being resistant to $100 \%$ relative humidity $((\mathrm{RH}) /$ moisture $)$. As the interest lies in showing the fitness for purpose in real life situations, it would be more appropriate to evaluate the functionality against the requirements of a specified application. In this way, the new materials are not evaluated based on pre-defined properties of plastic but based on the actual functioning of the application. For new bio-based products, it may be difficult to comply to these standards; this is because they exhibit a different set of characteristics previously not envisaged. This may not, however, imply that these products are unsafe for the targeted application and may lead to the unnecessary exclusion of products.

Finally, bio-based product producers are often requested by users to certify special characteristics of their products, such as biodegradability, sustainability, the share of biological content. In certain cases, a variety of similar or overlapping certifications exist in the market (e.g., compostability). The large amount of certification schemes is perceived as a hurdle for bio-based product producers as they are responsible for the related costs and administrative burdens. Moreover, for certain aspects, such as the risk of indirect land use change (ILUC), certification options are still at an infancy level (Majer et al., 2018). Finally, the overwhelming number of sustainability certification schemes (e.g., ecolabels) and their lack of harmonization, further confuse consumers, therefore representing a barrier linked to communication and image.

\section{RESULTS}

\section{Elements of a Supportive Regulatory Framework for the Bio-Based Economy}

This section presents the main results of the second round of the Delphi study, and Figure 3 provides an overview of the important features that, according to the participants, should be considered in a supportive regulatory framework for the bioeconomy. The different categories of features were derived from the answers of the first round, and their importance was ranked by the experts in the second round. This was done by adopting a Likert scale, from 0 "not important" to 5 "very important.

The introduction of a carbon tax for all products is considered by experts as the most important measure to be included in a supportive regulatory framework. More specifically, a carbon tax will level the current playing field of bio-based products, vis-à-vis fossil-based products (Carus et al., 2011). Considering that certain bio-based products emit fewer GHG emissions (EC, 2018), bio-based products will benefit from the introduction of revenues for GHG emissions. A carbon tax could be implemented as $\mathrm{CO}_{2}$ tax (i.e., $\mathrm{CO}_{2}$ emissions are taxed) or as fossil carbon tax (i.e., a tax on the fossil carbon contained in fossil resources). Tax benefits and financial incentives for innovative biobased products were also proposed (e.g., research allowances). 
Figure 3. Features of a supportive regulatory framework for the bio-based economy

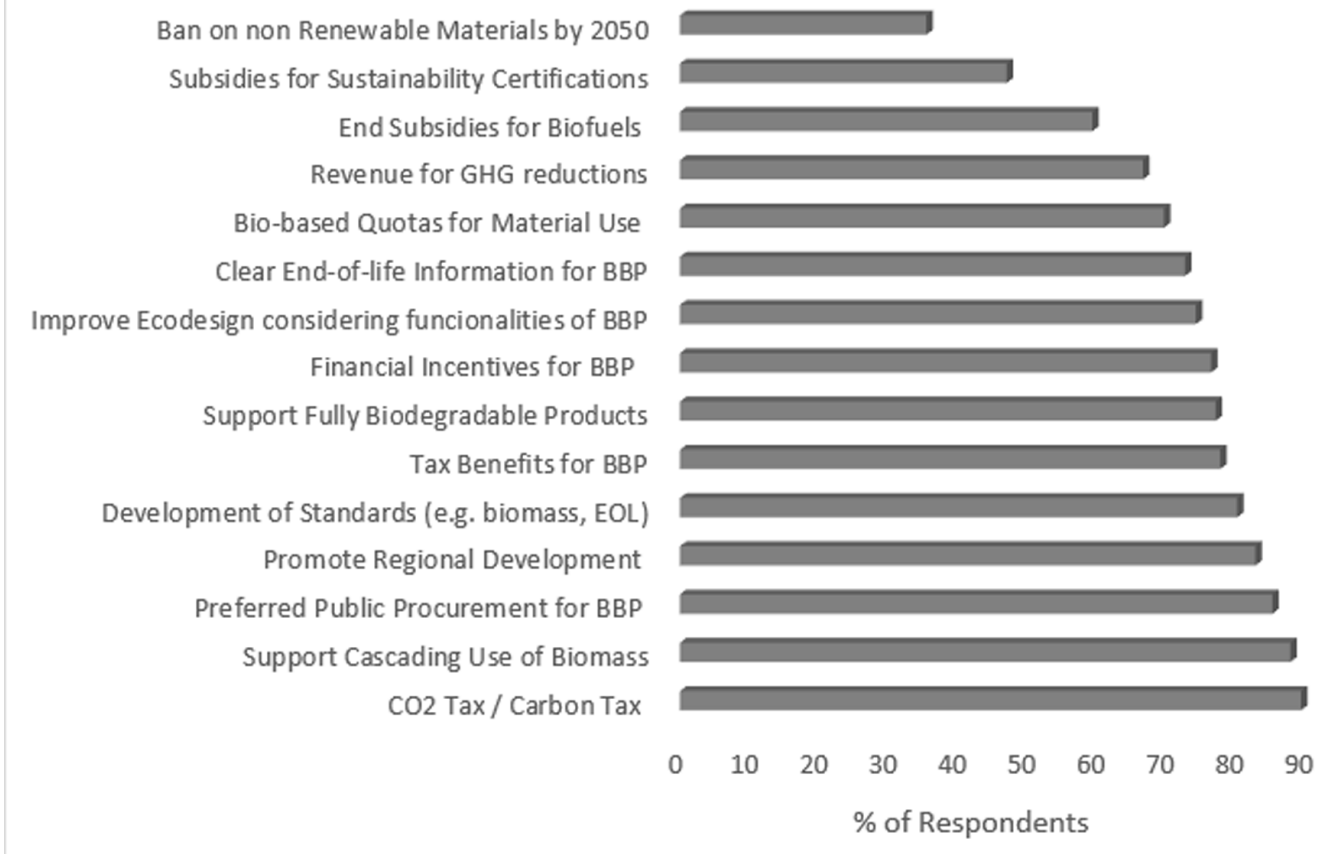

Supporting the cascading use of biomass was also classified as "very important". Possible suggestions on how to operationalize different principles of the cascading use will be described in this results section of this paper.

Preferred public procurement for sustainable bio-based products represents a relevant feature of a supportive regulatory framework and a great channel for increasing demand for more sustainable products. It should be complemented by the request for sustainability certification for all products, including traditional and fossil-based products, and by the roll out of corresponding standards and labels. The development of sustainability criteria throughout the entire value chain is essential to ensure a level playing field for all products (Ladu et al, 2019a). However, in order to reduce administrative and monetary barriers to bio-based product producers, the introduction of subsidies for sustainability certifications should be considered.

To level the playing field between the material use of biomass versus energy, it was proposed to end subsidies for biofuels. Another alternative could be the introduction of quotas and blending mandates for the material use of biomass: in the long run, a ban on non-renewable material should be introduced. Ladu et al. (2019b) proposed the introduction of a "Renewable Materials Directive" for accelerating the transition from fossil-based materials to bio-based alternatives. This should be coupled with the development of biomass related standards (e.g., quality and availability) to increase consumers' confidence in biomass quality.

A supportive regulatory framework should address the entire life-cycle of a product, including the after use phase. With the overall goal of reducing waste, the production of fully biodegradable products for specific applications (e.g., mulch films) should be supported, and this should be coupled with improvements in eco-design requirements considering the ability of bio-based products. For the consumers and waste collectors, it is important to have clear information on how the products should 
be disposed of after use. Carrying out strong communication actions in order to inform the public about the benefits of bio-based products will increase their awareness and willingness to buy them.

Finally, it is considered very important to establish a regulatory framework that enables unlocking the potential of the bioeconomy in promoting local development. The establishment of agro-industrial value chains based on the sustainable use of biomass are important measures for making bio-based products more competitive. Indeed, these value chains play an important role in developing strategies that aim at promoting investments to agro-enterprises, facilitating knowledge sharing between them, and, in general, for further expanding the role-played by agriculture in economic growth (UN, 2017).

\section{Elements Towards the Establishment of a Level Playing Field for Bio-Based Products}

An important element towards the establishment of a level playing field for bio-based products is the implementation of long-term policies and policy instruments that are independent of governmental changes and provide ambitious but realistic goals. The low price of fossil-based products and the existing blending mandate for biofuels hinder the development opportunities of the industrial material use of biomass. The adoption of long-term regulations will create needed trust for companies and increase their reliability on bio-based products and their willingness to invest.

The policy framework should be scientifically robust, comprehensive and consistent across all related sectors (e.g., in agriculture in order to ensure a sustainable supply and cost-efficient feedstock). It should consider several environmentally damaging factors (e.g., $\mathrm{CO}_{2}$ emissions, impacts on biodiversity, land use and climate change) and related social impacts and costs. It should be focused on increasing public awareness for both companies and consumers. This could be done by organizing training and awareness campaigns focused on increasing the motivation of the consumer when choosing products. Information should be easy to understand; in addition, functionality and sustainability issues should be communicated in a scientifically correct way without being misleading. In this sense, according to some experts, quality and performance standards could help customers to help guide their market choices.

A supportive regulatory framework should include demand support measures (e.g., green public procurement), as well as incentives for R\&D and training for bio-based products. Legislative acts that aim to foster the emergence of bio-based products and limit the costs of environmental externalities, as well as promoting the economy of circularity (e.g., through the application of specific fiscal measures) should be designed.

It is important to bear in mind that several regulatory requirements imply additional costs and time expenditure for companies. This may lead to delays in the market introduction of bio-based products. However, these requirements are necessary mechanisms to control the products that are entering the market, and cannot, therefore, be avoided. For example, the registration of new materials in the $\mathrm{REACH}^{2}$ regulation results in additional direct and indirect costs. Materials that are not directly included in the regulation must be shown and ensure compliance with the regulation. This administrative process for entering new products is costly and time consuming. In this sense, several ways to overcome these hurdles were proposed. One way was to simplify the administrative procedures for registering new products in REACH. Another way was to provide subsidies to cover costs linked to compliance with certain certification scheme requirements.

\section{Enhance Principles of Cascading use of Biomass}

Cascading use principles for biomass utilization are proposed as a way of maximizing resource efficiency and reducing negative environmental impacts of the production of bio-based products. Cascading use can be defined as the efficient utilization of resources by using residues and recycled materials to extend total biomass availability within a given system (Reichenbach et al., 2016). Another line differentiates between "cascading use" in terms of a vertical use hierarchy (e.g., recycling) and "co-production" in terms of a horizontal use hierarchy, which refers to the utilization of side streams and 
residues (Reichenbach et al., 2016). The German Environmental Agency (UBA) defines cascading use as the approach of using biomass that has already been processed (at least one more time) for material or energy purposes, distinguishing between single-stage cascade (bio-based products - energy) and multi-stage cascade (bio-based products - bio-based materials - energy) (Fehrenbach et al., 2017).

To date, the realization of cascade potential is minor and the potential of biomass cascades have been largely ignored. Currently, residues (e.g., lignocellulosic) are mostly used for energy generation. In this sense, there is a need to identify clear principles for the operationalization of cascading use in order to help companies consider cascading use, not only as a policy guidance indicator for sustainability. A consistent definition of the term cascading use across all sectors is lacking and its integration into existing legislature differs widely among Member States. A common strategy for supporting the operationalization of the term "cascading use of biomass" is needed, and according to the interviewed experts, it should promote:

i) The use of natural resources for as long as possible.

ii) Reuse and recycling.

iii) The use of side-streams and waste as biomass for material use.

Experts argue that these principles should be integrated in relevant regulations (e.g., Circular economy package, Construction Products Regulation (CPR), etc.) and should be developed by the EC together with relevant stakeholders. In addition, in order to strengthen the use of the cascading principle, it would be important to support zero waste principles by developing standards on waste collection and treatment (Ladu et al., 2019a), and by providing incentives for using waste as feedstock instead of using fossil-based products.

The integration of cascading use principles into existing legislature differs widely among individual countries (Dammer et al., 2016). For example, in Germany, the bio-waste ordinance and the circular economy law (BioAbfV/KrWG) introduce regulations on collection quotas and recycling targets; however, they do not address the routes of use of the collected biomass, and do not provide any preference for either energy or material uses (in practice often supporting the direct energy use of waste wood) (IEA Bioenergy, 2016). In Flanders, electricity producers can only use wood if the wood stream is not used as an industrial resource. This system is meant to support the creation of the cascading hierarchy of materials over energy applications of the biomass (Birdlife).

\section{Enhancing the Use of Waste as a Feedstock}

Large amounts of solid food waste are currently buried in landfill, and liquid food waste is released into public sewer systems. High transport and landfill costs, as well as strict governmental regulations, have led to the development of alternative utilization options of food processing waste. The selection of an appropriate process to recover materials and energy from food waste largely depends on the characteristics of the waste, the desired forms of bioenergy and bio-based products to be produced, as well as their economic feasibility (Wang, 2013). Incorporation of price-advantaged feedstocks (such as organic and wet-waste materials) have been highlighted by experts as upcoming innovations that could have an added benefit in solving local and regional waste disposal related issues. However, other experts pointed out that market mechanisms are volatile and hard to predict. As soon as a market exists for such feedstock, it is difficult to say how price structures will develop and whether they will still provide an advantage.

Currently, the valorization of organic waste into fertilizers is endorsed by the new EU fertilizer regulation, in which common rules about the conversion of bio-waste into raw materials that can be used to manufacture fertilizers are provided (Reicyhenbach et al., 2016 and EC, 2019).

However, unlocking the potential of using waste as feedstock needs a supportive regulatory framework, starting from an update of the current Waste Framework Directive (WFD ${ }^{3}$ ). Figure 4 shows 


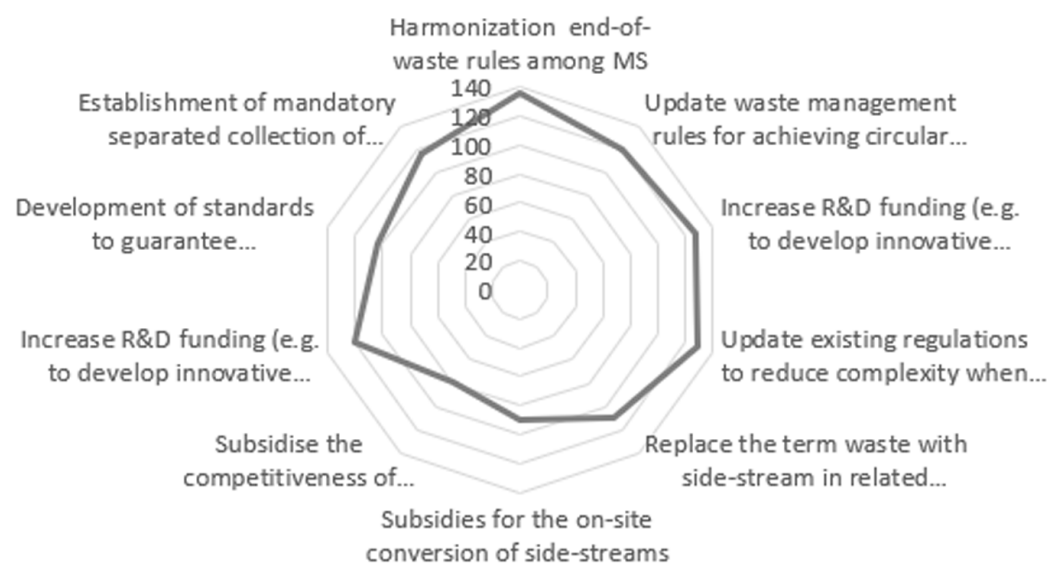

an overview of measures identified in the 2-round Delphi exercise that, according to experts, should be implemented for supporting the use of waste as feedstock in the production of bio-based products.

As shown in Figure 4, there is a need to provide a legal status to the terms "residues" and "sidestreams" currently not included in the WFD, which only defines "waste" and "by-products".

Another problem is related to the fact that regulations do not allow the use of waste as feedstock for material use, unless the waste ceases to be waste (complying with requirements included in art. 6 of the WFD), and is considered a by-product (complying with requirements included in art. 5 of the WFD). In addition, the EU's rules on end-of-waste criteria are not harmonized, and whether a material is a 'by-product' or 'waste' must be decided on a case-by-case basis, possibly leading to different interpretations. According to article 6, as long as the criteria for waste have not been set at a European level, member states may decide on the status of the waste on a case-by-case basis. In other words, MS has the right to decide whether certain waste has ceased to be waste or not. This has led to a situation where MS developed strict criteria that are impeding the use of waste to produce bio-based products. In this sense, the EU should provide guidance for selecting appropriate criteria and support their implementation. A potential solution could be that the EU develops an EU harmonized horizontal standard on end-of-waste (see Figure 4), and each MS should develop a decree with criteria for specific products and specify when waste ceases to be waste (Ladu et al., 2019a). The EU should provide guidelines and solutions to facilitate the multilateral recognition of national approaches among MS.

Another concern is the conflict between the chemicals policy and the waste policy. Both policies have the same objectives: waste prevention and elimination or at least minimization of the use of very high concern substances. However, there is a difference between the "product not-allowed substances" and the "waste not-allowed substances", produced due to the contamination of waste by the presence of the legacy substances. These are defined as substances whose use was lawful in products at the time of their production, but that have subsequently been subjected to regulatory control by the time these products become waste. The existence of legacy substances and how to deal with them when contained in products represents a relevant hurdle. The problem is linked to the fact that there is a 
time difference between the lifetime of a product (defined here as the time a product needs to reach its end-of-life) and the time a substance (that might be contained in the product) takes to be classified as "legacy substance".

\section{Standards that are in Need of Revision}

The most important and/or pressuring barriers identified by the experts are related to:

- Compostability (EN 13432)

- Non-functional specifications within standards

- Biodegradability of lignin

\section{Compostability}

The EN 13432 "Packaging: requirements for packaging recoverable through composting and biodegradation" was developed in 2000. Compostability is a characteristic of a product, packaging or associated component that allows it to biodegrade under specific conditions (e.g., a certain temperature, timeframe). This standard defines how quickly and to what extent a biodegradable plastic must degrade under industrial composting conditions. The EN 13432 is a harmonized European standard linked to the European Directive on Packaging and Packaging Waste (94/62/EC). The standard prescribes requirements for disintegration (among other requirements): after 12 weeks, at least $90 \%$ of the product should be able to pass through a $2 \times 2 \mathrm{~mm}$ mesh.

The general opinion is that when the characteristics of bio-based plastics are in line with the EN 13432 standard, industrial composters can compost them without complications. Bio-based plastics usually do not have problems with complying with these requirements. However, composters run composting installations in less time than the described 12 weeks. The Dutch Waste Management Association (VA) states that composting time is around 2-3 weeks, and that at some composting installations the composting time is even shorter: between 5 and 18 days. As a result, bio-based plastics cannot be fully composted in the short composting cycles, and composters will sieve out the (bio) plastics beforehand. According to interviewed bio-based plastic producers, the minimum composting time is six weeks. The composters state that they must comply with the Fertilizers Act (EU, 2019), which states that there cannot be any plastics (bio-based or fossil) in the compost. As a result, most bio-based plastics currently end up in incineration facilities.

The conclusion from research and interviews is that changing the standard (EN 13432) is not the solution for the current challenges in the market situation. The opposition of composters to biodegradable products does not depend on the standard as much as the fact that they do not accept any compostable plastic products. However, the Standard, which was developed in 2000, should be in line with current practice. As composting processes have changed considerably since then, a revision of the Standard is recommended. The goal is to come to an agreement that matches the industrial practices of today and the near future with what can be achieved for compostable plastics and for products for which composting may have benefits.

\section{Non-Functional Specifications Within Standards}

For many years, product standards (i.e., those that specify requirements to be fulfilled by a product or a group of products) have been developed to determine the fitness for purpose of the products. The easiest way to show fitness for purpose for products was to demonstrate this against the characteristics of a certain material. However, most of these "standards of performance" have been developed considering only those characteristics specific to fossil-based products. This means that the requirements within the standard are, for example, currently based upon the characteristics of plastic. To demonstrate fitness for purpose, new materials are tested against the characteristics of plastic (e.g., plastic being resistant to $100 \% \mathrm{RH})$. These standards are developed to evaluate the characteristics of materials to 
evaluate whether they are fit for their purpose. It would, however, be more appropriate to look at the final functioning of the product instead of evaluating the materials that are used in the product. This would be more inclusive for new materials to enter the market. In the end, it is about the performance of the product and not about the characteristics of the material.

One good example of a standard whose specifications are designed based on fossil materials is the climate test. During transport, vibrations, shocks, knocks, pressure loads, changes in temperature or changes in air humidity can have a great influence on products and/or packaging. Customers of packaging products producers (usually) require a climate test to be successfully passed to ensure that the shipment can deal with these possible issues. Climate testing involves exposing a package or a product to different controlled levels of temperature and humidity inside a calibrated test chamber. This simulates a range of climatic changes that may occur during distribution. The test can expose flaws in packaging, such as seals and glue joints becoming impaired and packaging being damaged, reducing its ability to protect the product. The conditions for these climate tests are not, however, based on actual transportation situations and the high relative humidity $(\mathrm{RH})$; therefore, part of the test is not representative for real life situations.

The atmospheric test is perceived to be too strict as the conditions in real life are never as extreme as in the climate tests. The tests are historically based on plastic being resistant to $100 \% \mathrm{RH}$, so only faults in the package (design) would then lead to water leakage and therefore test failures. Due to their hydrophilic nature, bio-based materials respond differently to changes in the RH (and to a lesser extent temperature). For this reason, bio-based materials (can) fail the climate test, although the test is set to determine failures in the product and not in the materials used. At the time the standards were developed, alternative materials entering the market were not considered. This issue will be brought to the attention of the responsible standardization committees. Several other standards were identified during the research where their intention did not agree with the execution. An important example is standards that exclude recycled materials. These were also flagged to the responsible standardization committees.

\section{Biodegradability of Lignin}

The definition of biodegradable is that a material is capable of undergoing biological anaerobic or aerobic degradation leading to the production of $\mathrm{CO}_{2}, \mathrm{H}_{2} \mathrm{O}$, methane, biomass, and mineral salts, depending on the environmental conditions of the process.

When bio-based materials are biodegradable, their constituents can be returned to nature by means of organic recycling based on biological processes, enabling biogenic circular routes. The biodegraded material becomes nutrients for new plants and trees; these can then become new bio-based products, therefore closing the loop. There are several standards that demonstrate the biodegradability of products (EN 14995, EN 13432, EN 14046, ISO 14855)). These standards prescribe for degradation to $\mathrm{CO}_{2}$, water, methane, biomass and minerals within a certain time (typically $90 \%$ within 6 months).

Products containing lignin cannot meet this requirement. Lignin is a recalcitrant biopolymer, meaning that it resists degradation. When a plant is degraded in soil, the polysaccharides are quickly degraded to $\mathrm{CO}_{2}$ and water, while the last $30 \%$ of the plant, the lignin, is converted to soil organic matter (humins, humic acid). The latter is essential for soil to be productive. Lignin will, in the end, degrade to $\mathrm{CO}_{2}$, but this takes longer than the prescribed six months in the standard tests.

The EU demands that all polymers or coatings used in controlled release fertilizers must be biodegradable. The problem arises when biodegradability is assessed with one of the above standards. As a result, lignin will not be allowed as a controlled release polymer in fertilizers (not degraded to $\mathrm{CO}_{2}$ and water, only to humic acid). This is contradictory as lignin is possibly the soundest polymer to use; the soils need the lignin. As several parties in the market have recently raised this issue, the European Commission is currently looking into this. 


\section{CONLCUSION AND SUGGESTIONS}

In order to establish a cutting-edge bio-based economy in Europe, a coherent, well-coordinated and favourable regulatory and standardization framework is needed. The regulatory and standardization framework should support the unlocking of the potential of the bio-based economy and should ensure even competition among all products. To support the achievement of this goal, this paper identifies needs for updates of the existing regulatory and standardization framework governing the bio-based economy. It provides suggestions to implement the identified updates in view of supporting the market uptake of bio-based products.

Regulatory and standardization suggestions are provided for different existing market barriers identified by experts. These include:

- The absence of a level playing field for bio-based products, both versus biofuels and fossil-based products.

- The lack of a generally accepted end-of-life option for bio-based products.

- Barriers related to end-of-life and performance standards specifications.

To identify possible solutions to overcome these barriers, a foresight activity (consisting of a 2-round Delphi Survey) was conducted. The final objective was to identify desirable updates of the regulatory and standardization framework.

The results showed that there is a need to establish long-term policies independent of governmental changes, coupled with the introduction and adoption of policy instruments, such as the introduction of a carbon tax for all products. It is also important to adopt strategies and actions directed at increasing the competitiveness of bio-based products, such as sustainability criteria for all products and strong communication actions to inform consumers about the benefits of bio-based products.

To increase the efficiency in biomass production and production processes, there is a need to identify the elements to be included in a strategy for promoting cascading use of biomass. Cascading principles should be integrated in relevant regulations (e.g., circular economy package, Construction Products Regulation (CPR), etc.), and should be developed by the EC together with relevant stakeholders. The operationalization of cascading principles would benefit from standards on waste collection and treatment, and by providing incentives for using waste as feedstock instead of using fossil-based feedstock.

The integration of cascading use principles into existing legislature differs widely among individual countries (Dammer et al., 2016). In Germany, for example, the biowaste ordinance and the circular economy law (BioAbfV/KrWG) introduced regulations on collection quotas and recycling targets; however, they do not address the routes of use of the collected biomass, and do not provide any preference for either energy or material uses (in practice often supporting the direct energy use of waste wood). In Flanders, the electricity producers can use wood only if the wood stream is not used as an industrial resource. This system is meant to support the creation of the cascading hierarchy of materials over energy applications of the biomass (Birdlife).

In order to unlock the potential of waste as a feedstock, several clarifications and updates of the existing regulatory framework are suggested. Currently, existing gaps and misalignments within the WFD are hampering the use of waste to produce bio-based products. Proposed solutions are linked to the need to adhere to the definitions that have legal status in the WFD; only the terms "waste" and "by-products" provided by the directive would be used. Article 6 should also be updated in order to provide clear, harmonized criteria to distinguish between waste, and waste that ceases to be waste. Additionally, Article 4 on waste hierarchy should be updated to appropriately consider various Endof-life (EOL) options, in particular those of interest for bio-based products. Other suggestions include:

- Conducting ecotoxicity tests and risk assessment analysis, where appropriate, to classify waste; 
- Harmonizing the WFD and the Circular Economy Package to facilitate optimal resource use (including waste);

- Providing harmonized European guidance on preferred EOL options; and

- Harmonizing waste classifications in the EU to appropriately consider the waste of bio-based products

To conclude, several standards need to be updated to support the uptake of bio-based products. Also, the promotion of a sustainable bio-based economy in Europe is considered of great importance. A relevant suggestion related to standardization is to involve the industry more intensively during its development. This will reduce misfits in practise. For the identified barriers related to standards, solutions were formed in cooperation with the project partners, selected value chains and additional stakeholders. These solutions were communicated within the correct standardization channels.

\section{ACKNOWLEDGMENT}

This paper is based on research conducted under the implementation of the STAR4BBI project (Standards and Regulations for the Bio-based Industry), financed by the Bio-based Join Undertaking Industry (BBI-JU). STAR4BBI supported the adaption of the regulatory framework and of relevant standards for selected existing value chains, with the overall objective of establishing a coherent and favourable regulatory framework that helps develop a cutting-edge bio-based economy for Europe. 


\section{REFERENCES}

Baker, J., Lovell, K., \& Harris, N. (2006). How expert are the experts? An exploration of the concept of 'expert' within Delphi panel techniques. Nurse Researcher, 14(1), 59-70. Retrieved from https://pdfs.semanticscholar.or g/7a6d/4f45d873e60b0b74604fbde33a39b8209b85.pdf. doi:10.7748/nr2006.10.14.1.59.c6010 PMID:17100214

BBI JU. (2017): Strategic Innovation and Research Agenda (SIRA). Retrieved from https://www.bbi-europe. eu/sites/default/files/sira-2017.pdf

Blind, K. (2008). Regulatory foresight: Methodologies and selected applications. Technological Forecasting and Social Change, 75(4), 496-516. doi:10.1016/j.techfore.2008.02.004

Bos, H., van den Oever, M., Dammer, L., Babayan, T., Ladu, L., Clavell, J., \& Vrins, M. (2018): Market entry barriers report. STAR4BBI project. Retrieved from http://www.biobasedeconomy.eu/app/uploads/ sites/2/2018/09/Please-click-here-to-access-deliverable-2.1.pdf

Carus, M., Carrez, D., Kaeb, H., Ravenstijn, J., \& Venus, J. (2011): Level Playing Field for Bio-based Chemistry and Materials. Greengran. Retrieved from https://www.greengran.com/download/Policy\%20paper\%20on\%20 Bio-based\%20Economy\%20in\%20the\%20EU.pdf

Dammer, L., Bowyer, C., Breitmayer, E., Eder, A., Nanni, S., Allen, B., \& Essel, R. et al. (2016). Mapping study on cascading use of wood products. World Wide Fund for Nature. Switzerland: WWF.

EC. (2012). Innovating for Sustainable Growth: A Bioeconomy for Europe. Retrieved from https://op.europa. eu/en/publication-detail/-/publication/1f0d8515-8dc0-4435-ba53-9570e47dbd51

EC. (2013). A new EU Forest Strategy: for forests and the forest-based sector. Retrieved from https://ec.europa. eu/agriculture/forest/strategy/communication_en.pdf

EC. (2014). Towards a circular economy: A zero waste programme for Europe. Retrieved from http://ec.europa. eu/environment/circular-economy/pdf/circular-economy-communication.pdf

EC. (2018). A sustainable Bioeconomy for Europe: Strengthening the connection between economy, society and the environment. Retrieved from https://eur-lex.europa.eu/legal-content/EN/TXT/PDF/?uri=CELEX:520 $18 \mathrm{DC} 0673 \&$ from $=\mathrm{EN}$

EC. (2019). Laying down rules on the making available on the market of EU fertilising products and amending Regulations (EC) No 1069/2009 and (EC) No 1107/2009 and repealing Regulation (EC) No 2003/2003. Retrieved from https://eur-lex.europa.eu/legal-content/EN/TXT/PDF/?uri=CELEX:32019R1009\&from=EN

European Union. (2009). Directive 2009/28/EC of the European Parliament and of the Council of 23 April 2009 on the promotion of the use of energy from renewable sources and amending and subsequently repealing Directives 2001/77/EC and 2003/30/EC. Retrieved from https://eur-lex.europa.eu/legal-content/EN/ ALL/?uri=CELEX:32009L0028

European Union. (2009). Directive 2015/1513 of the European Parliament and of the Council of 9 September 2015 amending Directive 98/70/EC relating to the quality of petrol and diesel fuels and amending Directive 2009/28/EC on the promotion of the use of energy from renewable sources (Text with EEA relevance). Retrieved from https://eur-lex.europa.eu/legal-content/EN/TXT/?uri=CELEX\%3A32015L1513

European Union. (n.d.). Proposal for a Directive of the European Parliament and of the Council on the Promotion of the use of Energy from Renewable Sources (recast). Retrieved from https://eur-lex.europa.eu/legal-content/ EN/TXT/?uri=CELEX:52016PC0767R\%2801\%29

Fehrenbach, H., Koppen, S., Kauertz, B., Detzel, A., Wellenreuther, F., Breitmayer, E., . . von Geilbler, J. (2017): Biomass Cascades, Increasing resource efficiency by cascading use of biomass - from theory to practice. Umweltbundesamt. Retrieved from https://www.umweltbundesamt.de/sites/default/files/medien/1410/ publikationen/2017-06-13_texte_53-2017_biokaskaden_summary.pdf

Giaoutzi, M., \& Sapio, B. (Eds.). (2013). Recent developments in foresight methodologies (Vol. 1). Berlin: Springer Science and Business Media. doi:10.1007/978-1-4614-5215-7

JRC. (2015) Delphi Survey. Retrieved from http://forlearn.jrc.ec.europa.eu/guide/4_methodology/meth_delphi. htm 
Ladu, L., \& Clavell, J. (2018). Identification of technological trends in selected value chains. Biobased Economy. Retrieved from http://www.biobasedeconomy.eu/app/uploads/sites/2/2018/09/Please-click-here-to-accessdeliverable-3.1.pdf

Ladu, L., Clavell, J., Quitzow, R., Costenoble, O., Vrins, M., van den Berg, J., . . Partanen, A. (2019a) Policy paper on strategy for development of an RCS framework. STAR4BBI project. Retrieved from https://www. star4bbi.eu/app/uploads/sites/11/2019/09/D3.3-Sustainability-Certification-for-all-Products_final.pdf

Ladu, L., Clavell, J., Quitzow, R., Costenoble, O., Vrins, M., van den Berg, J., . . Partanen, A. Bos H., van den Oever M. Vural Gursel I. (2019b) Regulation Action Plan. STAR4BBI project. Retrieved from https://www. star4bbi.eu/app/uploads/sites/11/2019/09/D4.4_Regulation-action-plan_final.pdf

Ladu, L., \& Quitzow, R. (2017). Bio-based economy: Policy Framework and Foresight Thinking. In P. Morone, F. Papendiek, \& V. E. Tartiu (Eds.), Food Waste Reduction and Valorisation (pp. 167-195). Springer International Publishing. doi:10.1007/978-3-319-50088-1_9

Ladu and Clavell. J. (2019) Regulatory and Standardization needs in bio-based industries, STAR4BBI project, Deliverable 3.2 of the STAR4BBI project. Retrieved from https://www.biobasedeconomy.eu/app/uploads/ sites/2/2018/09/FINAL-D3.2.pdf

Linstone, H. A., \& Turoff, M. (Eds.). (2002). The Delphi Method: Techniques and applications. Newark, NJ: New Jersey Institute of Technology.

Majer, S., Wurster, S., Moosmann, D., Ladu, L., Sumfleth, B., \& Thrän, D. (2018). Gaps and Research Demand for Sustainability Certification and Standardisation in a Sustainable Bio-Based Economy in the EU. Sustainability, 10(7), 2455. Retrieved from https://www.mdpi.com/2071-1050/10/7/2455. doi:10.3390/su10072455

Reichenbach, J., Mantau, U., Vis, M., Essel, R., \& Allen, B. (2016). Study on the Optimised Cascading Use of Wood. EU publications. Retrieved from https://publications.europa.eu/en/publication-detail/-/ publication/04c3a181-4e3d-11e6-89bd-01aa75ed71a1

T., vom Berg C., Dammer L., Partanen A. Bos H., van den Oever M. Vural Gursel I. (2019a) Policy paper on strategy for development of an RCS framework. STAR4BBI project. Retrieved from https://www.star4bbi.eu/ app/uploads/sites/11/2019/09/D3.3-Sustainability-Certification-for-all-Products_final.pdf

Vecchiato, R., \& Roveda, C. (2014). Foresight for public procurement and regional innovation policy: The case of Lombardy. Research Policy, 43(2), 438-450. doi:10.1016/j.respol.2013.11.003

Vis, M., Mantau, U., Allen, B., Essel, R., \& Reichenbach, J. (2016). Study on the optimised cascading use of wood. European Commission.

\section{ENDNOTES}

https://www.iso.org/standards.html

REACH is a regulation of the European Union, adopted to improve the protection of human health and the environment from the risks that can be posed by chemicals, while enhancing the competitiveness of the EU chemicals industry

3 The general framework for waste management is provided by Directive 2008/98/EC99 on waste, which was later amended by Directive (EU) 2018/851. 
Luana Ladu (Ms) holds a M. Sc. in Economics from UFBA (Brazil) and a Degree in Law and Business Administration (Master equivalent) from Bocconi University (Italy). She has several years of experience as consultant and researcher in the field of international development and sustainable development, with a focus on sustainability, circularity and bio-based economy. She is currently working as a Research Fellow at the Chair of Innovation Economics of the Technische Universität Berlin in the framework of the STARPROBIO, STAR4BBI and Bio Top projects, where she is responsible for the implementation of different foresight exercises (including scenario development and Delphi surveys), regulatory framework analysis and market studies. She is also pursuing a PHD in economics, planned to be finalized by June 2020. A list of her current publications is Retrieved from https://www. inno.tu-berlin.de/menue/about_us/team/luana_ladu_msc/parameter/de/Ms. Ladu has many years of professional experiences abroad, including 3 years as a consultant at the ICT for Development Division of the Inter-American Development Bank (IADB), developing and implementing its "ICT in Governance and ICT security for the public sector" program as well as its ICT strategy entitled "Connecting the Majority". During her professional experience as project manager and project director in a consulting firm, she was involved in the implementation of numerous donorfinances projects in the field of Education, Vocational Training and Capacity Building sector.

Minique Vrins is a standardization consultant at NEN, the Netherlands Standardization Institute. Working at the Energy division, she is responsible for several subjects within the renewable energy field. Topics as green investments, sustainability certification, bioplastics and massbalance are part of her portfolio. She is responsible for the Better Biomass and the Biobased content certificates. She also works on several EU research projects on regulations and standards in the bioeconomy. 